\title{
SFN Gain in Broadcast Networks
}

\author{
David Plets, Wout Joseph, \\ Leen Verloock, and Luc Martens \\ Wireless and Cable-IBBT \\ Dept. of Information Technology, \\ Ghent University, Belgium \\ Email: david.plets@intec.ugent.be
}

\author{
Pablo Angueira \\ University of the Basque \\ Country (UPV/EHU) \\ Bilbao, Spain
}

\author{
José Antonio Arenas \\ Telefónica Móviles España \\ Spain
}

\begin{abstract}
For broadcast networks, the Single-Frequency Network (SFN) mode is an alternative to the well-known MultiFrequency Network (MFN) mode, where instead of transmitters operating at different frequencies, all base stations use the same frequency. Besides an expected improvement of the quality of service due to the more homogeneous distribution of received signal strength, some areas will also show a degraded quality caused by the SFN echoes. In this paper, the SFN gain is defined as a parameter describing potential gain or interference. An unambiguous methodology to obtain the actual SFN gain is presented and the variation of the gain is investigated for a DVB-H network as a function of the signal strength difference received from different transmitters. This SFN gain can be used for coverage planning of future broadcast networks.
\end{abstract}

\section{INTRODUCTION AND OBJECTIVES}

When operators deploy a broadcast network, they want to keep the total cost as low as possible. This can be achieved by keeping the number of base stations and their transmitting power as low as possible. From a theoretical perspective, a Single Frequency Network (SFN) will deliver the same quality with a certain amount of reduction in transmitted power. This assumption is based on the fact that the field strength will be homogeneously distributed due to the spatial diversity associated to SFN networks. Nevertheless, the quality of service in the SFN area will depend on the number and nature of the received signals (number of transmitters, relative delays, and relative amplitudes). Furthermore, the equalization method and synchronization stages of the reference receiver will also be relevant to the final shape of the service area. The SFN gain parameter was proposed at the same time that the SFN concept was developed (in practical terms) for digital broadcasting in the early nineties. A review on the literature related to SFN gain calculations [1]-[12] shows that most references have dealt with the SFN gain optimistically, just considering the improvement in the homogeneity of the behavior of the field strength, leaving aside potential selfinterference and both synchronization and equalization problems associated to the receiver. For most of the cases studied in the literature, the SFN gain calculation has been based on field strength measurements, trying to obtain the statistical improvement in the field strength distribution. This paper will show that this should not always be the case, and will provide a methodology to calculate a meaningful value of the SFN gain for network planning purposes [13]. Also, it should be noted that previous work has been carried out for traditional broadcasting scenarios to fixed receivers. In cases where the receivers are portable (either indoor or outdoor) or mobile, the number of SFN echoes and the extension of the area where they are present will increase.

The proposed procedure will be applied on a real DVB-H network in Ghent, Belgium and the SFN gain at a certain location will be calculated as a function of the difference in signal strength received from the different transmitters (overlapping degree). Also, the influence of the reception quality in MFN operation on the SFN gain will be analyzed. The DVB-H network, the measurement equipment and the collected data are discussed in Section II. Section III defines the SFN gain and Section IV discusses the processing of the measurement samples. In Section V, quality categories and transmitter overlapping are defined, Section VI discusses the results, and finally, the conclusions are presented in Section VII.

\section{TRANSMitTing NETWORK AND AVAILABLE MEASUREMENTS}

\section{A. Transmitting network}

The transmitting network is located in the city of Ghent (Belgium), a mixture of a suburban and an urban environment. The SFN consists of three base station antennas and operates at a frequency of $602 \mathrm{MHz}$. The channel bandwidth is $8 \mathrm{MHz}$. Fig. 1 shows a map of Ghent with the location of the three base station transmitters marked with red circles with white dots in it. All transmitting antennas (Tx) are omnidirectional and vertically polarized. The heights of these $\mathrm{Tx}$ are $\mathrm{h}_{\mathrm{Tx}_{1}}=57 \mathrm{~m}$, $\mathrm{h}_{\mathrm{Tx}_{2}}=64 \mathrm{~m}$, and $\mathrm{h}_{\mathrm{Tx}_{3}}=63 \mathrm{~m}$, respectively. The EIRP (Equivalent Isotropically Radiated Power) used for these Tx is $36.62 \mathrm{dBW}, 39.93 \mathrm{dBW}$, and $40.90 \mathrm{dBW}$, respectively. The constellation used for the tests is 16-QAM $1 / 2$ with an MPE-FEC (Multi-Protocol Encapsulation-Forward Error Correction) rate of $7 / 8$, corresponding with a useful bit rate of $9.68 \mathrm{Mbps}$. This constellation is preferred because of its satisfactory behavior regarding both bit rate and coverage area [14]-[16]. The used guard interval is $1 / 8$ and the FFT mode is $4 \mathrm{~K}$. 


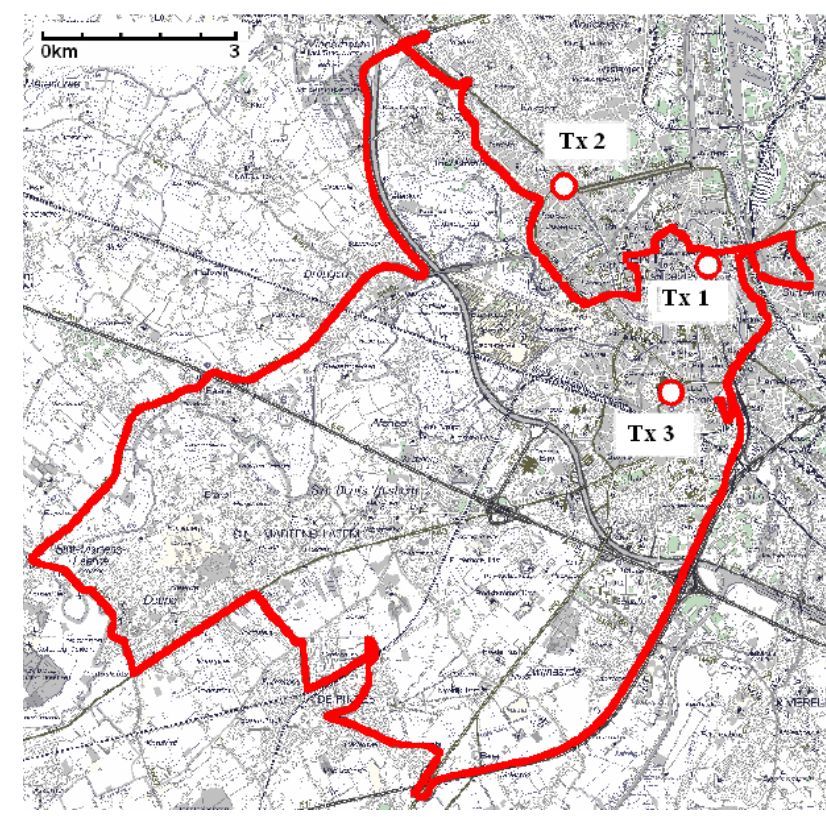

Fig. 1. Map of Ghent with the 3 transmitters (red circles with white dots) and indication of the measurement route.

\section{B. Measurement equipment}

The measurements are performed with a tool implemented on a PCMCIA (Personal Computer Memory Card International Association) card with a small receiver antenna $\mathrm{Rx}$. The gain of the antenna is - $5 \mathrm{dBi}$ [15]. The PCMCIA card is plugged into a laptop, which is used to perform the measurements.

Every $0.5 \mathrm{~s}$, a sample is recorded, while the receiver is either locked or unlocked. A locked receiver can receive DVB-H frames, which are either correct or incorrect. Incorrect tables can (sometimes) be corrected by the MPE-FEC code. The tool logs parameters as MER (modulation error ratio), FER (Frame Error Rate), MFER (Multi-Protocol Encapsulation FER), and electric-field strength. MFER is the ratio of the number of residual erroneous frames (i.e., not recoverable) and the number of received frames [17]. FER is the ratio of the number of erroneous frames before MPE-FEC correction and the number of received frames [17]. Location and speed are recorded with a GPS device. Measurements are performed inside a small van at a height of about $1.5 \mathrm{~m}$ above ground level.

\section{Available data}

The methodology proposed in this paper has been developed using measurements taken along a $50 \mathrm{~km}$ route. The route stretches from the very centre of Ghent to the municipalities that surround Ghent (see Fig. 1). The SFN gain behavior has been analyzed using four network configurations, which, in one scenario comprises all the transmitters being active (and synchronized) as a SFN network, and in the rest of scenarios, each one of the transmitters will be the active transmitter, being the rest switched off. The four scenarios (each with a scenario ID) that have been investigated, are summarized in
Table I. Each scenario provides us with a collection of samples recorded along the track. Each sample consists of position data (GPS coordinates), signal data (electric-field strength $\mathrm{E}$ $[\mathrm{dB} \mu \mathrm{V} / \mathrm{m}]$ ), and Modulation Error Ratio (MER) [dB]. When an MPE (Multi-Protocol Encapsulation) table [18] is received, it is also recorded whether this table is correct, incorrect, or corrected after MPE-FEC correction. About 10,000 samples are collected for each scenario.

\begin{tabular}{|l|l|}
\hline Description & scenario ID \\
\hline \hline Transmitter Belgacom (Tx 1) active, other Tx off & Scen $_{1}$ \\
\hline Transmitter Bemilcom (Tx 2) active, other Tx off & Scen $_{2}$ \\
\hline Transmitter Ledeganck (Tx 3) active, other Tx off & Scen $_{3}$ \\
\hline Transmitters Belgacom, Bemilcom, Ledeganck active & Scen $_{\text {SFN }}$ \\
\hline
\end{tabular}

TABLE I

DESCRIPTION OF THE FOUR INVESTIGATED SCENARIOS.

\section{DEFINITION OF SFN GAIN}

This paper proposes to evaluate the SFN gain SFNG based on the actual performance of a standard receiver and also on the specific digital broadcast standard. The parameter to be used in each case might differ (in some cases there will be more than one candidate). In any case this figure must reflect the actual quality of service being received. This paper will use the MER [dB] as an indication of the quality. Obviously, the MER will be closely related to field strength levels $\mathrm{E}$ $[\mathrm{dB} \mu \mathrm{V} / \mathrm{m}]$ but it will reflect much more accurately all reception conditions, including the SFN effect, positive or negative (and not only signal strength variations). SFNG is then defined as the MER in SFN mode minus the MER in MFN mode. It should be noted that the field strength values have been used in this paper to evaluate the real SFN effect, especially when obtaining statistical results from the measurements. SFN gain effect will be significant only in locations where the field strength values received from more than one transmitter are comparable. Locations where one transmitter is dominant, even in the case of having all the transmitters on, have not been considered as spots with SFN gain (either positive or negative). The general SFNG definition has been empirically analyzed using the experimental data described in Section II-C. The data sets were formed by measurements along a route, with a strong spatial variation associated to mobile reception in an urban environment. In order to remove the fast variation, the measurement samples were grouped in spatial segments of a certain length (see Section IV). The definition of the SFNG then becomes:

$$
\mathrm{SFNG}=\mathrm{MER}_{\mathrm{Scen}_{\mathrm{SFN}}}-\max \left(\mathrm{MER}_{\mathrm{Scen}_{\mathrm{i}}}\right)[\mathrm{dB}]
$$

with $\mathrm{MER}_{\mathrm{Scen}_{\mathrm{SFN}}}$ the median MER in a segment when all three transmitters are active and $\max \left(\mathrm{MER}_{\mathrm{Scen}_{\mathrm{i}}}\right)$ the maximum of the median MER values of $\operatorname{Scen}_{i}$, with $i=1,2$, 3 (only one transmitter active). Thus, for each segment, only two of the four scenarios will be used for calculation: Scen $_{\mathrm{SFN}}$ 


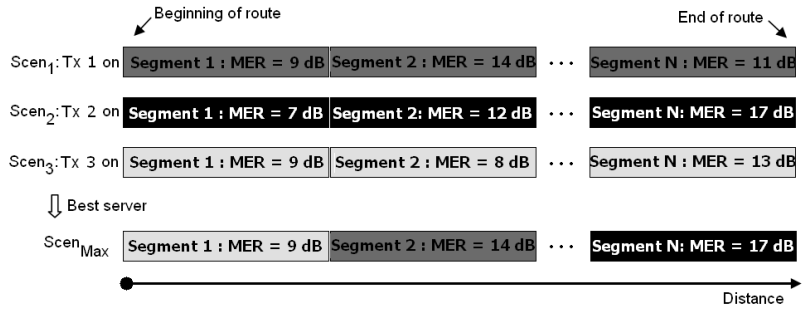

Fig. 2. Process of creating Scen $_{\mathrm{Max}}$ data set.

and the one-transmitter scenario with the highest median MER in that segment. The latter scenario represents the 'best server' case. As mentioned previously, being the reception mobile and considering a significant amount of Non Line-of-Sight (NLOS) situations, the dominant transmitter will be changing from location to location. In order to smooth this variation and have a reference transmitter for each segment, same segments of different drives were compared, and a new 'best server' route representing the set of segments with best reception was created. This route is called in the paper $\mathrm{Scen}_{\mathrm{Max}}$. This Scen $_{\text {Max }}$ data set will represent the 'ideal MFN scenario'. The process is explained in Fig. 2. The aim of considering a maximum scenario is to include the fact that the best server for one location in a MFN scenario will not necessarily be the closest transmitter, specially in the case of mobile and portable reception.

\section{Processing methodology of the SAmples}

The field tests were based on mobile DVB-H measurements along a $50 \mathrm{~km}$ route. The measurement route was repeated four times, with different transmitter configuration (Scenarios 1, 2, 3 and Scen $_{\mathrm{SFN}}$ ). Each time, the measurement car drove the same route, but obviously, the instantaneous measurements were not taken at exactly the same location. In order to make a proper comparison between all routes, a spatial alignment procedure is applied using the position data from the GPS device. The alignment procedure starts with a division of the route into smaller segments of a certain well-chosen segment length, e.g. $100 \mathrm{~m}$. One of the four drives is taken as reference and divided into segments. The sample at the end of each segment is called "border sample". Then, the corresponding border samples for the other three trajectories are obtained by picking the sample that is located the closest to the border sample of the first trajectory, only considering samples starting from the first sample after the previous border sample. Excellent trajectory synchronization was obtained using this procedure (average difference between segments lengths is approximately $5 \mathrm{~m}$ for a segment length of $100 \mathrm{~m}$ ).

Not all segments were retained for further processing: firstly, because of lack of statistical relevance at certain segments. Data were discarded where Scen $_{\mathrm{SFN}}$ or Scen $_{\mathrm{Max}}$ did not contain more than 5 samples. When short segment lengths are chosen, a lot of segments will therefore be discarded, less kilometers are retained for shorter segment lengths). Secondly, when the resulting actual segment length for Scen $_{\mathrm{SFN}}$ differs more than $20 \%$ from the segment length for $\mathrm{Scen}_{\mathrm{Max}}$, the segment is again discarded, because of a possible alignment error. The remaining segments are assumed to be valid segments. A segment length of $100 \mathrm{~m}$ was used. This resulted in $38.7 \mathrm{~km}$ retained segments (out of $50 \mathrm{~km}$ ).

\section{DEFINITION OF QUALITY CATEGORIES AND OVERLAPPING DEGREE}

The SFNG will reflect the SFN coverage improvement with respect to the MFN situation. This evaluation is not easy to convey: some of the areas might present degradation whereas others might be improved. Also, the SFNG should be evaluated using data from areas (segments in this paper) where the SFN effect is relevant. The comparison study will provide the changes in quality of service (classified as perfect, good, doubtful, and low) as a function of the intensity of the SFN overlapping. Based on our observations of the behavior of the SFNG, we assume that a relevant SFN effect will occur provided two (or more) transmitters are received with a relative field strength difference lower than $9 \mathrm{~dB}$. We observed that if at least one transmitter was received $9 \mathrm{~dB}$ above the rest, the effect was less relevant in most cases (at least if the SFN is composed of 3 transmitters only). Applying these statements to DVB-H, four quality categories were defined (perfect, good, doubtful, and low quality), based on the MFER values [17]. These MFER values are the percentage of locations with valid tables (method explained in [15]). Table II shows these four quality categories based on MFER limits, and their associated upper and lower MER. The overlapping degree between transmitters will be analyzed as $\mathrm{E}_{\mathrm{diff}}[\mathrm{dB}] . \mathrm{E}_{\mathrm{diff}}$ is defined (for each segment), as the difference between the electric-field strength due to the dominant transmitter and the electric-field strength due to the second strongest transmitter.

$$
\mathrm{E}_{\mathrm{diff}}=\mathrm{E}_{\text {median }}^{\text {DominantTx }}-\mathrm{E}_{\text {median }}^{\text {SecondStrongestTx }}[\mathrm{dB}]
$$

When $\mathrm{E}_{\text {diff }}$ is small (i.e., high overlapping degree) and the signal strengths thus similar, we expect to observe an SFNG. Fig. 3 shows the overlapping degree $\mathrm{E}_{\text {diff }}$ between the transmitters for each valid segment. The color code is explained in the figure caption. The overlapping degree is mostly only small (red) for segments far away from all transmitters. Also small parts between transmitters 1 and 2, and transmitters 2 and 3 are orange or red. The parts of the route that are colorless (only a black trail) in Fig. 3 (and all further route figures) are the segments that were discarded due to bad synchronization. In Fig. 3 five zones are indicated where SFNG has a particular behavior.

\section{RESUlts}

\section{A. SFN gain and $\mathrm{E}_{\mathrm{diff}}$}

Two different effects are associated to SFN operation. Some locations will show a contribution of the SFN effect to the coverage (positive SFNG) and at other locations the SFN effect will be degrading the coverage (negative SFNG). Fig. 4 shows the SFNG along the route. Figs. 3 and 4 show that segments 


\begin{tabular}{|l||r|r|}
\hline Quality & MFER & MER [dB] \\
\hline \hline Perfect & MFER $<1 \%$ & MER $>17.12$ \\
\hline Good & $1 \%<$ MFER $<5 \%$ & $14.26<$ MER $<17.12$ \\
\hline Doubtful & $5 \%<$ MFER $<10 \%$ & $13.46<$ MER $<14.26$ \\
\hline Low & MFER $>10 \%$ & MER $<13.46$ \\
\hline
\end{tabular}

TABLE II

FOUR QUALITY CATEGORIES, THE CORRESPONDING MFER LIMITS, AND THEIR UPPER AND LOWER MER.

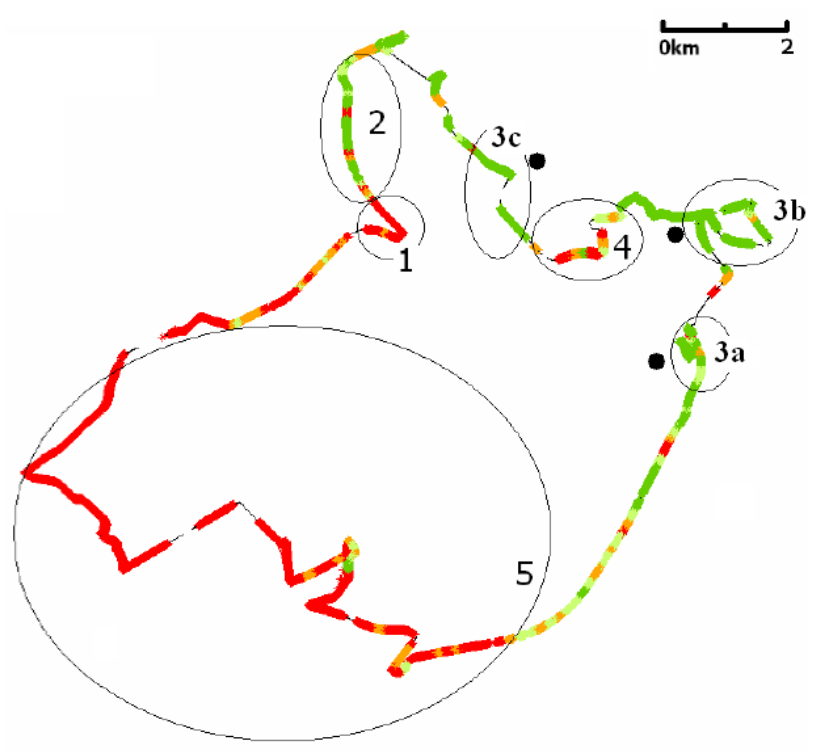

Fig. 3. Overlapping degree $\mathrm{E}_{\text {diff }}$ between the transmitters for each valid segment (red: $\mathrm{E}_{\mathrm{diff}}<3 \mathrm{~dB}$, orange: $3 \mathrm{~dB}<\mathrm{E}_{\text {diff }}<6 \mathrm{~dB}$, light green: $6 \mathrm{~dB}$ $<\mathrm{E}_{\text {diff }}<9 \mathrm{~dB}$, and dark green: $9 \mathrm{~dB}<\mathrm{E}_{\text {diff }}$ ).

that are not served (further away from the transmitter), show relevant overlapping degrees (low $\mathrm{E}_{\mathrm{diff}}$ ). In those areas SFNG is mostly positive (yellow and green). This happens because the MER in the MFN cases is too low because the received field strength from any of the transmitters is too weak. When operating the network in SFN mode, the MER increases, due to the contribution of the three transmitters. Close to an active transmitter in the SFN mode (zones 3a, 3b, and 3c in Fig. 3), $\mathrm{E}_{\text {diff }}$ is mostly larger than $9 \mathrm{~dB}$ and the gains there tend to be negative (red and orange). For the segments 'in the middle' between the three transmitters (low $\mathrm{E}_{\text {diff }}$ ), the gain is positive. This indicates again that low values of $\mathrm{E}_{\text {diff }}$ correspond with positive SFNGs.

Table III lists the number and the percentage of retained segments in the different quality categories for Scen $_{\text {Max }}$ and Scen $_{\text {SFN }}$ and the difference when switched from Scen Max $_{\text {to }}$ Scen $_{\mathrm{SFN}}$. The data is classified for statistical analysis into three different categories of overlapping degree: no limit on $\mathrm{E}_{\text {diff }}$ (All segments), and $\mathrm{E}_{\text {diff }}$ limited to a maximum of $6 \mathrm{~dB}$ and $3 \mathrm{~dB}$. Table III shows that areas with significant overlapping (this happens in segments in the middle between two or three transmitters (zones 1 and 4 in Fig. 3) and in

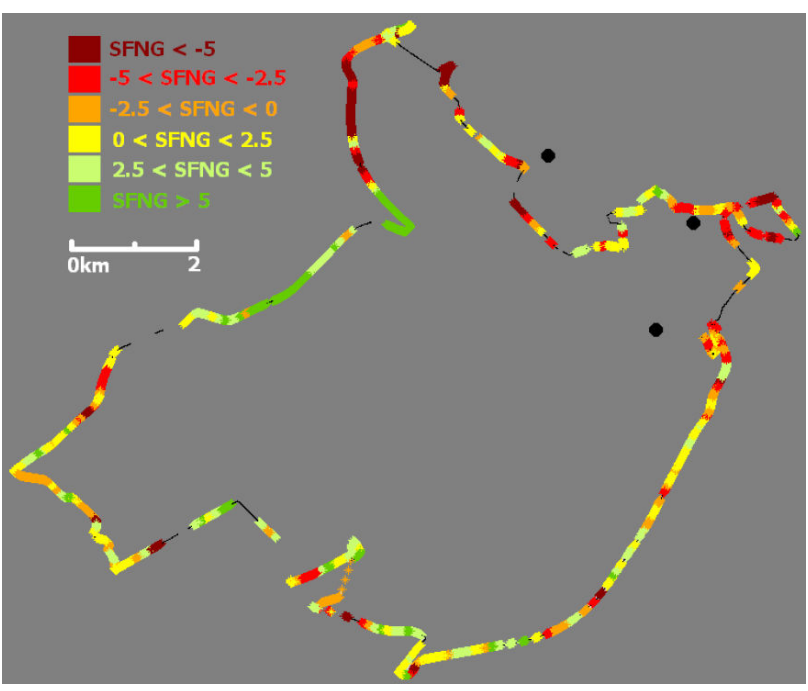

Fig. 4. SFNG in the different segments along the route.

the segments far away from all three transmitters (zone 5 in Fig. 3)), there is a positive gain. For an overlapping degree corresponding to an $\mathrm{E}_{\text {diff }}$ lower than $3 \mathrm{~dB}$, the number of perfect segments increases from 4 to 20 when the operation mode is changed from MFN to SFN (compared to 124 vs. 127 when there is no upper limit on $\left.\mathrm{E}_{\text {diff }}\right)$. As expected, this effect is higher when $\mathrm{E}_{\text {diff }}$ is lower.

If the whole set of data is studied, no relevant SFNG is observed (as shown in Table III). This is a major conclusion from the methodology presented in this paper, being even more relevant in the case of dense broadcast networks for mobile and portable services in urban areas, where the number, relative delay, and relative amplitudes of signals from different transmitters in the SFN will be very variable. In these scenarios, in order to take advantage of the SFN gain, and also in order to avoid coverage degradation caused by the SFN, it will be necessary to have an accurate planning tool suitable for portable and mobile reception in urban environments. These tools have been widely used in cellular network planning during the last decade and will be necessary for broadcast SFN planning for portable devices [19], [20].

Table IV shows for different ranges of $E_{\text {diff }}$ the median SFNG in the different quality categories, the number of segments available, and the standard deviation. Segments of perfect quality $(-2.87 \mathrm{~dB})$ and segments with $\mathrm{E}_{\text {diff }}>9 \mathrm{~dB}(-$ $3.4 \mathrm{~dB}$ ) mostly have a negative gain. This corresponds with our previous findings that gains are negative close to each of the three transmitters. Segments of good and doubtful quality are likely to have positive gains $(0.91 \mathrm{~dB}$ and $2.2 \mathrm{~dB}$, respectively). Low quality segments (mostly far from all transmitters, $\mathrm{E}_{\text {diff }}$ $<3 \mathrm{~dB}$ ) have positive gains as well $(2.2 \mathrm{~dB})$, but are not really representative for a real network. The standard deviations are mostly around 3 to $4 \mathrm{~dB}$. Generally, Table IV shows that the larger the overlapping degree (or the lower $\mathrm{E}_{\text {diff }}$ ), the higher SFNG. 


\begin{tabular}{|c|c|c|c|c|c|c|c|c|c|c|c|c|c|c|c|}
\hline & \multicolumn{3}{|c|}{ Perfect } & \multicolumn{3}{|c|}{ Good } & \multicolumn{3}{|c|}{ Doubtful } & \multicolumn{3}{|c|}{ Low } & \multicolumn{3}{|c|}{ All categories } \\
\hline & SFNG & \#Segm & $\sigma$ & SFNG & \#Segm & $\sigma$ & SFNG & \#Segm & $\sigma$ & SFNG & \#Segm & $\sigma$ & SFNG & \#Segm & $\sigma$ \\
\hline$E_{\text {diff }}<3$ & -7.92 & 4 & 8.08 & 2.6 & 12 & 4.13 & 3.86 & 2 & 0.77 & 1.98 & 149 & 4.14 & 1.98 & 167 & 4.50 \\
\hline $3<\mathrm{E}_{\text {diff }}<6$ & -0.13 & 9 & 1.80 & 0.41 & 5 & 2.03 & -1.6 & 4 & 3.33 & 3.61 & 40 & 3.55 & 1.63 & 58 & 3.58 \\
\hline $6<\mathrm{E}_{\mathrm{diff}}<9$ & 1.6 & 13 & 3.77 & 0.82 & 17 & 3.13 & 2.3 & 4 & 2.28 & 1.41 & 13 & 3.69 & 1.35 & 47 & 3.42 \\
\hline $9<\mathrm{E}_{\text {diff }}$ & -3.4 & 98 & 4.48 & 0.7 & 14 & 3.56 & 1.31 & 2 & 1.57 & -0.24 & 1 & 0 & -3.04 & 115 & 4.54 \\
\hline All segments & -2.87 & 124 & 4.68 & 0.91 & 48 & 3.37 & 2.2 & 12 & 2.62 & 2.2 & 203 & 3.99 & 0.76 & 387 & 4.82 \\
\hline
\end{tabular}

TABLE IV

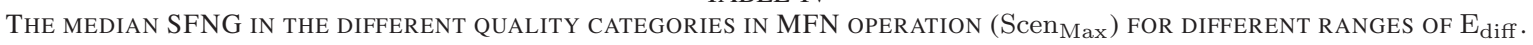

\begin{tabular}{|r|r|r|r|r|r|r|}
\hline \multicolumn{1}{|c|}{ Quality } & \multicolumn{7}{|c|}{ Scen $_{\text {Max }}$} & \multicolumn{2}{c|}{ Scen $_{\text {SFN }}$} & \multicolumn{2}{c|}{ Difference } \\
\hline & \#Segm & \%Segm & \#Segm & \%Segm & \#Segm & \%Segm \\
\hline & \multicolumn{7}{|c|}{ All segments } \\
\hline Perfect & 124 & 32.0 & 127 & 32.8 & 3 & +2.4 \\
\hline Good & 48 & 12.4 & 41 & 10.6 & -7 & -14.6 \\
\hline Doubtful & 12 & 3.1 & 10 & 2.6 & -2 & -16.7 \\
\hline Low & 203 & 52.5 & 209 & 54.0 & 6 & +3.0 \\
\hline & \multicolumn{7}{|c|}{$\mathrm{E}_{\text {diff }}<\mathbf{6 ~ d B}$} \\
\hline Perfect & 13 & 5.8 & 32 & 14.2 & 19 & +146.2 \\
\hline Good & 17 & 7.6 & 19 & 8.4 & 2 & +11.8 \\
\hline Doubtful & 6 & 2.7 & 5 & 2.2 & -1 & -16.7 \\
\hline Low & 189 & 84.0 & 169 & 75.1 & -20 & -10.6 \\
\hline & \multicolumn{7}{|r|}{$\mathrm{E}_{\text {diff }}<\mathbf{3 ~ d B}$} \\
\hline Perfect & 4 & 2.4 & 20 & 12.0 & 16 & +400.0 \\
\hline Good & 12 & 7.2 & 8 & 4.8 & -4 & -33.3 \\
\hline Doubtful & 2 & 1.2 & 0 & 0.0 & -2 & -100.0 \\
\hline Low & 149 & 89.2 & 139 & 83.2 & -10 & -6.7 \\
\hline
\end{tabular}

might be due to the difference in path length between these segments and transmitters 2 and 3 (or 2 and 1, respectively). As the environment is suburban, it is possible that the reflected signal from transmitters 1 and 3 arrive too late compared to signals received from transmitter 2, this way impairing the reception quality.

Thus, we can conclude that SFN operation improves good and doubtful reception and decreases perfect quality reception. However, the MER mostly remains high enough to maintain perfect reception quality. Thirdly, a lot of zones west of transmitter 2 have a high decrease in reception quality with a highly negative SFNG (see Fig. 4, zone 2 in Fig. 3).

TABLE III

COMPARISON OF THE QUALITY OF THE RETAINED SEGMENTS FOR Scen $_{\text {Max }}$ AND Scen SFN FOR THREE DIFFERENT RESTRICTIONS WITH REGARD TO $\mathrm{E}_{\text {diff }}$ : NO LIMIT ON $\mathrm{E}_{\text {diff }}$ (ALL SEGMENTS), AND $\mathrm{E}_{\text {diff }}$ LIMITED TO A MAXIMUM OF 3 DB AND 6 DB.

\begin{tabular}{|c|c|c|c|c|c|}
\hline & \multicolumn{4}{|c|}{ Scen $_{\text {SFN }}$} \\
\hline & & Perfect & Good & Doubtful & Low \\
\hline \multirow{4}{*}{$\begin{array}{c}\mathscr{U} \\
\tilde{n}\end{array}$} & Perfect & $71 \%$ & $9 \%$ & $2 \%$ & $18 \%$ \\
\hline & Good & $42 \%$ & $31 \%$ & $2 \%$ & $25 \%$ \\
\hline & Doubtful & $25 \%$ & $33 \%$ & $8 \%$ & $33 \%$ \\
\hline & Low & $8 \%$ & $5 \%$ & $2 \%$ & $84 \%$ \\
\hline
\end{tabular}

TABLE V

NUMBER OF SEGMENTS MOVED FROM ONE QUALITY CATEGORY TO ANOTHER WHEN OPERATION MODE CHANGES FROM MFN ( Scen $_{\text {Max }}$ ) TO SFN ( Scen $\left._{\mathrm{SFN}}\right)$.

\section{B. Comparison of SFNG for segments with different reception qualities.}

In the following we will investigate 'the shift between quality categories' (defined in Table II) when the operation mode is switched from MFN to SFN. Table V shows for all four quality categories the number of segments that are lost to other quality categories when the network operation mode is switched from MFN ( $\operatorname{Scen}_{\mathrm{Max}}$, left part of Table V) to SFN ( Scen $_{\mathrm{SFN}}$ ). Firstly, Table V shows that low quality segments are unlikely to obtain much improvement (84\% of low quality remains low quality). These are mostly segments far away from all three transmitters, so despite the positive gain there, the quality remains low. Secondly, 'doubtful' and 'good' segments are more likely to be improved. $42 \%$ of the good segments are improved to perfect segments, while 27\% (2\% of good to doubtful $+25 \%$ of good to low) have a decrease in quality due to interference. $58 \%(25 \%+33 \%)$ of the doubtful tables are improved in quality (to perfect and good), while $33 \%$ gets worse (to low). Finally, 18\% of 'perfect' segments become low quality segments. For the most part, these are the segments in zone 2 of Fig. 3 (dark red in Fig. 4). This

\section{SFNG in link budget and summary}

Finally, we calculate a value for SFNG which can be used in link budget calculations. We should only look at segments on the border between two transmitters (where the signal strength received by both transmitters is similar) and therefore we will retain the segments where $E_{\text {diff }}$ is lower than $9 \mathrm{~dB}$ and where the reception quality in Scen $_{\text {Max }}$ is doubtful or good. Low quality segments are excluded in order to exclude zone 5 (not realistic for an actual network) and zone 2 (unrealistic positioning, other transmitters would surround this zone in a real network). With these restrictions and from Table IV, the median SFNG equals $1.1 \mathrm{~dB}$ with a standard deviation of $3.3 \mathrm{~dB}$ (good and doubtful segments with $\mathrm{E}_{\mathrm{diff}}<9 \mathrm{~dB}$ in Table IV are retained). This gain of $1.1 \mathrm{~dB}$ is compared to an ideal MFN, which is already better than a realistic MFN. A significant advantage of the use of an SFN, confirmed by experimental results is that the standard deviation on the MER decreases significantly: when the entire trajectory is 
considered, the standard deviation drops from $5.21 \mathrm{~dB}$ for Scen $_{\mathrm{Max}}$ to $2.69 \mathrm{~dB}$ for Scen $_{\mathrm{SFN}}$.

\section{CONCLUSIONS}

In this paper we have proposed a new methodology to obtain unambiguously the SFN gain. The method has been explained using experimental work from a DVB-H network in Ghent, Belgium. Four quality categories (perfect, good, doubtful, low) have been defined and their influence on the SFN gain has been analyzed. The relationship between the SFN gain and the geographical location has also been investigated. The results show that gain is negative on locations very close to one transmitter, but since the recorded MER there is high enough, it has no real negative influence on the reception quality. In general, when the whole set of data is studied, no relevant SFNG is observed, but on locations where at least two transmitters provide the receiver with a similar signal strength $\left(\mathrm{E}_{\mathrm{diff}}<9 \mathrm{~dB}\right)$, the $\mathrm{SFN}$ gain is positive and the reception quality is improved. An SFN gain of $1.1 \mathrm{~dB}$ with a standard deviation of $3.3 \mathrm{~dB}$ is obtained for locations on the border between network cells. Future studies may include the investigation of the SFN gain in networks with more transmitters in urban environments. It is expected that in a large city the number of transmitters received at a location might be much higher than three, affecting the behavior of the receiver and increasing the complexity of planning.

\section{ACKNOWLEDGMENT}

This work was supported by the IBBT-MADUF project, co-funded by the IBBT (Interdisciplinary institute for BroadBand Technology), a research institute founded by the Flemish Government in 2004, and the involved companies and institutions. W. Joseph is a Post-Doctoral Fellow of the FWO-V (Research Foundation - Flanders).

\section{REFERENCES}

[1] Instinct, "DVB-H Field Trials, Testing Mobile TV in Metz, France," 2005. [Online]. Available: http://dea.brunel.ac.uk/instinct/PublicDocs.htm\#Deliverables

[2] P. Talmola et. al, "Wing TV, Services to Wireless, Integrated, Nomadic, GPRS-UMTS \& TV handheld terminals," Tech. Rep., Nov. 2006. [Online]. Available: http://www.celtic-initiative.org/Projects/WINGTV/defaultasp

[3] G. Santella, R. D. Martino, and M. Ricchiuti, "Single frequency network (sfn) planning for digital terrestrial television and radio broadcast services: the italian frequency plan for t-dab," Vehicular Technology Conference, vol. 4, pp. 2307 - 2311, 17-19 May 2004.

[4] J. Boveda, G. Marcos, J.M. Perez, S. Ponce, A. Aranaz, "MER degradation in a broadcast mobile network," in 2009 IEEE International Symposium on Broadband Multimedia Systems and Broadcasting, Bilbao, Spain, 13-15 May 2009, paper No. mm09-71.

[5] D. Plets, L. Verloock, W. Joseph, L. Martens, E. Deventer, and H. Gauderis, "Weighing the Benefits and Drawbacks of an SFN by Comparing Gain and Interference caused by Operation," in 2009 IEEE International Symposium on Broadband Multimedia Systems and Broadcasting, Bilbao, Spain, 13-15 May 2009, paper No. mm09-34.

[6] S. G. Tanyer, T. Yucel, and S. Seker, "Topography Based Design of the T-DAB SFN for a Mountainous Area," IEEE Transactions on Broadcasting, vol. 43, no. 3, pp. 309-319, Sept 1997.

[7] S. I. Park, S. R. Park, H. Eum, J. young Lee, Y.-T. Lee, and H. M. Kim, "Equalization On-Channel Repeater for Terrestrial Digital Multimedia Broadcasting System," IEEE Transactions on Broadcasting, vol. 54, no. 4, pp. 752-760, Dec 2008.
[8] R. Rebhan and J. Zander, "On the Outage Probability in Single Frequency Networks for Digital Broadcasting," IEEE Transactions on Broadcasting, vol. 39, no. 4, pp. 395-401, Dec 1993.

[9] A. Ligeti and J. Zander, "Minimal Cost Coverage Planning for Single Frequency Networks," IEEE Transactions on Broadcasting, vol. 45, no. 1, pp. 78-87, March 1999.

[10] S. O'Leary, "Field Trials of an MPEG2 Distributed Single Frequency Network," IEEE Transactions on Broadcasting, vol. 44, no. 2, pp. 194205, June 1998.

[11] T. Prosch, "The Digital Audio Broadcast Single Frequency Network Project in Southwest Germany," IEEE Transactions on Broadcasting, vol. 40, no. 4, pp. 238-246, Dec 1994.

[12] A. Mattsson, "Single Frequency Networks in DTV," IEEE Transactions on Broadcasting, vol. 51, no. 4, pp. 413-422, Dec 2005.

[13] D. Kateros, D. Zarbouti, D. Tsilimantos, C. Katsigiannis, P. Gkonis, I. Foukarakis, D. Kaklamani, and I. Venieris, "DVB-T Network Planning: A Case Study for Greece," IEEE Antennas and Propagation Magazine, vol. 51, no. 1, pp. 91-101, Feb. 2009.

[14] D. Plets, W. Joseph, L. Martens, E. Deventer, and H. Gauderis, "Evaluation and Validation of the Performance of a DVB-H Network," in 2007 IEEE International Symposium on Broadband Multimedia Systems and Broadcasting, Orlando, Florida, USA, March 2007.

[15] D. Plets, W. Joseph, L. Verloock, E. Tanghe, L. Martens, E. Deventer, and H. Gauderis, "Influence of Reception Condition, MPE-FEC rate and Modulation Scheme on Performance of DVB-H Networks," IEEE Transactions on Broadcasting (Special Issue on Quality Issues in Multimedia Broadcasting), vol. 54, no. 3, pp. 590-598, 2008.

[16] D. Plets, W. Joseph, L. Verloock, E. Tanghe, L. Martens, H. Gauderis, and E. Deventer, "New Method to Determine the Range of DVB-H Networks and the Influence of MPE-FEC Rate and Modulation Scheme," EURASIP Journal on Wireless Communications and Networking, vol. 2009, article ID 524163. [Online]. Available: http://www.hindawi.com/journals/wcn/2009/524163.html

[17] ETSI, TR 102401 v1.1.1, "Digital Video Broadcasting (DVB); Transmission to Handheld Terminals (DVB-H); Validation Task Force Report," May 2005.

[18] G. Faria, J. A. Henriksson, E. Stare, and P. Talmola, "DVB-H: Digital Broadcast Services to Handheld Devices," Proceedings of the IEEE, vol. 94, no. 1, pp. 194-209, Jan. 2006.

[19] Y. Corre and Y. Lostanlen, "Three-dimensional urban em wave propagation model for radio network planning and optimization over large areas," IEEE Transactions on Vehicular Technology, vol. 58, pp. 31123123, Sept 2009.

[20] T. K. Sarkar, Z. Ji, K. Kim, A. Medouri, and M. Salazar-Palma, "A survey of various propagation models for mobile communication," IEEE Transactions on Antennas and Propagation, vol. 45, no. 3, pp. 51-82, 2003. 